\title{
Some Remarks about the College and Its Future
}

We are now 13 years old. Proverbally, we have reached our manhood and womanhood. But more likely we have only been thrown into the maelstrom of adolescence. This is our 7th congress and it seems we are in an appropriate identity crisis - who we are, where do we wish to go? We have lost our founding father. We have a membership of 400 . We have wandered from Kyoto to Jerusalem. Our attendance has been as high as 1,300 and as low as the current conference. It gives us an opportunity to ask if smaller more focussed congresses are better? Will they get us beyond the platitudes and reiterations of the past toward more mature formulations of integration and synthesis?

Perhaps we are establishing an identity. However, there are whole continents in which our presence and our effect is either limited or nonexistent. There is a second and a third world that we have failed to align. We have prestigious vice presidents and councillors, as well as a body of delegates whose use the Administration has tapped limitedly. We are a body without a head in the sense that we have failed in our efforts to establish a journal. The quality of our meetings has been increasingly good, as I am confident this congress will demonstrate. However, the work in their formation has been that of a few. We need to inquire of ourselves of the forwardness of our theories and of the originality of our research. How often do we confuse statistical correlations ofendless variables as proof and substantiation, independent of critical reasoning? Future administrations will need to develop communicative and directive skills in order to tap its officers, as well as its younger members at large to do the job that they have been expected to do. I believe that under the auspices of the Program Committee, with frequent communication, the officers and commitee chairpersons should be responsible for the organization of symposia in the area they share, drawing on their knowledge of the new and seminal work that is under investigation, often outside of our purview. The delegation and tendering of this responsibility will insure the quality ouf our presentations and discussions, allowing our congresses to be more scientific, more communicative, and more conceptual. Several of us believe that our congresses should return to the campus where there is a natural environment for the membership to interact and participate as scholars in a setting conducive for the intimacy of scholarship outside of, as well as within, our more formal sessions. Would this not be a more facile environment in which to bring in our students and associates from other disciplines? Within these settings, there Some Remarks about the College and Its Future 11

must be new names and younger faces. There need to be considered presentations supported by new and referenced research that has been assimilated and presented in a fashion generative of discussion

There is a question to what extent the globality that some of us have wandered into has eroded rather than extended the boundaries of psychosomatic research and education. There is a need to rethink the extent to which process and substance is balanced. Have our borders become indistinct? As a discipline, we are beset both within and without by those who would offer 
simple solutions, whether of process or substance, in terms that have become commonplace, such as stress response, behavioral medicine, general hospital psychiatry, holistic medicine, and others. For the most part, these are techniques and processes that are pragmatic. But when incorporated into psychosomatic medicine as such do they not obscure and obfuscate the basic concern of mind-body relationship in the milieu externa?

Thus the challenge of this congress will not only be that of attending and understanding the large number of papers presented, it is more the studied and reflective communication that these give rise to in the corridors and around the charming paths of this city of Hamburg. And while we are in these perambulations, I propose that we think about who we are, what we are doing, where we want to go, and who we want to be when we grow up? What kind of congresses do we wish to have? How frequently do we wish to meet and what is its reality? What is the optimal size for the interactions we wish to have? How generally and how specifically should each be fo-cussed? To what extent should we expose ourselves and our concepts to the evolving fields of inquiry around us?

C.P. Chase P. Kimball

President 